\title{
Facile mass production of thermally reduced graphene oxide
}

\author{
Seungjun Lee and Sungjin Park* \\ Department of Chemistry, Inha University, Incheon 402-751, Korea
}

\section{Article Info}

Received 8 September 2011

Accepted 7 December 2011

*Corresponding Author

E-mail: sungjinpark@inha.ac.kr

\section{Open Access}

DOI: http://dx.doi.org/

10.5714/CL.2012.13.1.048

This is an Open Access article distributed under the terms of the Creative Commons Attribution Non-Commercial License (http://creativecommons.org/licenses/ by-nc/3.0/) which permits unrestricted non-commercial use, distribution, and reproduction in any medium, provided the original work is properly cited.

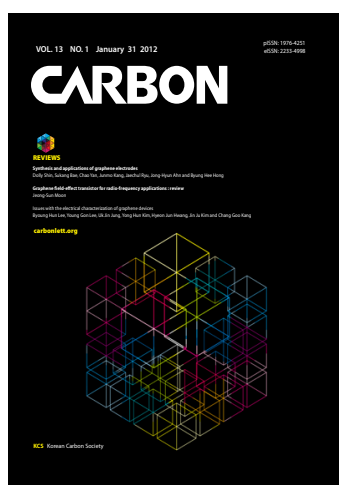

http://carbonlett.org

pISSN: 1976-4251

eISSN: 2233-4998

Copyright $\odot$ Korean Carbon Society

\begin{abstract}
Mass production of graphene-based materials, which have high specific surface area, is of importance for industrial applications. Herein, we report on a facile approach to produce thermally modified graphene oxide (TMG) in large quantities. We performed this experiment with a hot plate under environments that have relatively low temperature and no using inert gas. TMG materials showed a high specific surface area $\left(430 \mathrm{~m}^{2} \mathrm{~g}^{-1}\right)$. Successful reduction was confirmed by elemental analysis, X-ray photoelectron spectroscopy, thermogravimetic analysis, and X-ray diffraction. The resulting materials might be useful for various applications such as in rechargeable batteries, as hydrogen storage materials, as nano-fillers in composites, in ultracapacitors, and in chemical/bio sensors.
\end{abstract}

Key words: thermally reduced graphene oxide, mass production

\section{Introduction}

Recently graphene, which has an $\mathrm{sp}^{2}$ network of one atom thickness, has attracted much attention due to its excellent electrical, thermal, optical, and mechanical properties and its high surface area (theoretical value: $2600 \mathrm{~m}^{2} \mathrm{~g}^{-1}$ ) [1-3]. Production of chemically modified graphene (CMG) materials in large quantities is a great challenge for applications in batteries, as hydrogen storage materials, as nano-fillers in polymer composites, in ultracapacitors, and in sensors [4,5]. Chemical and thermal treatments of graphite oxide (GO), which is produced via oxidation of graphite, have been promising methods for the mass production of CMGs [3-7]. Herein, we report on a facile route to generate thermally reduced graphene oxide at relatively low temperature and under air.

GO has commonly been used as a starting material for the production of reduced graphene oxides, which have good physical properties [5]. Thermal reduction of GO usually requires a high temperature of around $1000^{\circ} \mathrm{C}$ and a stable environment filled with inert gas [3,7]. The chemical reduction of graphene oxide, which is exfoliated by simple sonication of GO in liquid phase, has shown good promise without high temperature processing [5]. However, sonication frequently leads to variations of material properties batch by batch and requires long processing time when large quantities are handled.

In this study, we present a facile route for the mass production of thermally reduced graphene oxide (thermally modified graphene oxide, TMG) using a hot plate and under air. This method requires only relatively low temperature heating and short time processing under air. The resulting materials showed high specific surface area $\left(430 \mathrm{~m}^{2} \mathrm{~g}^{-1}\right)$ in the Brunauer, Emmett, Teller (BET) test.

\section{Experimental Section}

\subsection{Sample preparation}

2.1.1. Production of GO

GO was produced by the modified Hummers method [8]. Natural graphite (1 g) was added 
to a $250 \mathrm{~mL}$ flask filled with Conc. $\mathrm{H}_{2} \mathrm{SO}_{4}$, followed by the addition of solid $\mathrm{KMnO}_{4}(350 \mathrm{mg})$ slowly in an ice bath $\left(0^{\circ} \mathrm{C}\right)$. After setting the temperature at $35^{\circ} \mathrm{C}$, the mixture was stirred with a magnetic stirring bar for $2 \mathrm{~h}$. Excess water was added to the mixture in an ice bath. Then, $\mathrm{H}_{2} \mathrm{O}_{2}$ was added until there was no gas being produced. This mixture was filtrated with a glass filter, which was then followed by washing with $\mathrm{HCl}$ solution in water (10 vol\%). Brown GO powder was dried under vacuum at room temperature for $12 \mathrm{~h}$.

\subsubsection{Thermally modified graphene oxide}

We added $100 \mathrm{mg}$ of dried GO to a $250 \mathrm{~mL}$ empty beaker. Then, the beaker was covered with aluminum foil that had many punched pores, made by a needle. We put the beaker on a hot plate set at $350^{\circ} \mathrm{C}$ for $10 \mathrm{~min}$ in the hood. The resulting black powders (TMG, $46 \mathrm{mg}$ ) were collected.

\subsubsection{Chemically reduced graphene oxide}

Chemically reduced graphene oxide (CReGO) was prepared as described in the literature [6], with slight modification. Aqueous suspensions of graphene oxide were prepared via sonication of $\mathrm{GO}$ ( $3 \mathrm{mg}$ of $\mathrm{GO} / 1 \mathrm{~mL}$ of $\mathrm{H}_{2} \mathrm{O}, 300 \mathrm{mg}$ of GO), and hydrazine monohydrate ( $1 \mu \mathrm{L}$ for $3 \mathrm{mg}$ of $\mathrm{GO}$ ) was added to the suspension, which was then heated and stirred at $80^{\circ} \mathrm{C}$ for $12 \mathrm{~h}$, yielding an agglomerated black powder. The resulting mixture was filtrated with a glass frit filter, then washed with distilled water, followed by drying under vacuum.

\subsection{Reagents and instruments}

\subsubsection{Reagents}

Natural graphite (SP-1 Bay Carbon), sulfuric acid (95\%, extra pure), potassium permanganate (extra pure; Daejung, Korea), hydrogen peroxide (30\%; Sigma-Aldrich, USA), $\mathrm{HCl}$ (10\% diluted in $\left.\mathrm{H}_{2} \mathrm{O}\right)$, and hydrazine monohydrate $(64 \sim 65 \%$, reagent grade, $98 \%$; Sigma-Aldrich) were used in this work. Water was purified by Human RO 180, Certified CE, ISO 9001/ISO 14001.

\subsubsection{Instruments}

Thermal properties of the TMG powder were measured by thermogravimetric analysis (TGA, STA409PC; TA Instruments, USA). BET specific surface areas of the powder samples were measured with a Belsorp-Mini II 475 from BEL Japan Inc. (Japan). Combustion-based elemental analysis was done with an EA1110-FISONS (ThermoQuest Italia S.P.A, Italy) for C, N, and $\mathrm{H}$ elements and with a FlashEA 1112 (Thermo Finnigan, Italy) for elemental O. X-ray diffraction (XRD) patterns were obtained with a Micro-Area Xray Diffractometer (D/MAX-2500; Thermo Science Corporation, USA). Field emission scanning electron microscopy (FE-SEM; Hitach S-4200, Japan) measurement was used. X-ray photoelectron spectroscopy (XPS) spectra were measured on an X-ray photoelectron spectrometer (ESCALAB 250; VG Scientifics, England). FTRaman spectra of powder samples were obtained with a BRUKER RFS 100/S (Bruker, Germany).

\section{Results and Discussion}

GO has been a promising precursor to make thermally re-

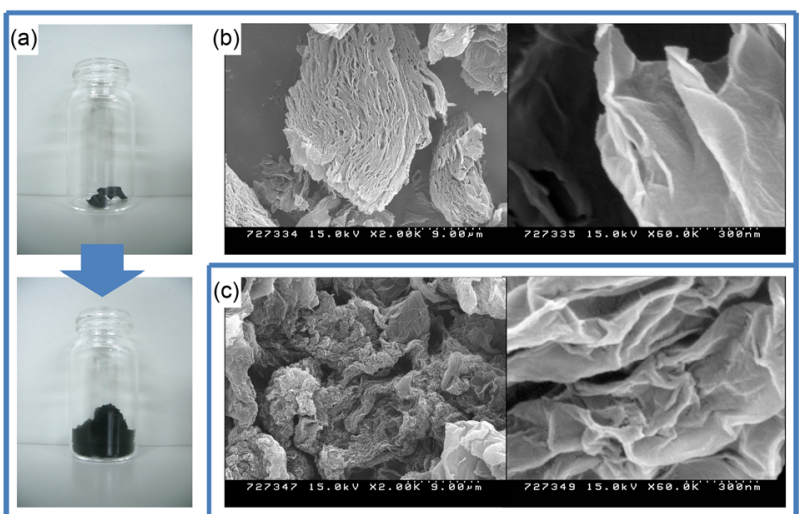

Fig. 1. Photographs of (a) $100 \mathrm{mg}$ of graphite oxide powder (top) and $46 \mathrm{mg}$ of thermally modified graphene oxide (TMG) (bottom). Scanning electron microscopy images (b) of TMG and (c) of chemically reduced graphene oxide.

duced graphene oxide in large quantities [7,9]. Rapid heating of GO materials results in the reduction of graphene oxide as well as in the simultaneous exfoliation of thin reduced graphene oxide platelets. However, the thermal treatments require high cost processing such as extremely high temperature $\left(\sim 1000^{\circ} \mathrm{C}\right)$ in an air-free chamber $[3,7]$. In this work, we used a simple method to produce thermally modified graphene materials with a facile and cheap treatment.

A beaker containing GO powder was put on a hot plate, which was set at $350^{\circ} \mathrm{C}$ (real temperature would be lower than $350^{\circ} \mathrm{C}$ ) under air. After $\sim 30 \mathrm{sec}$, the brown GO powder was popped, yielding black and floppy powders. The beaker was covered with aluminum foil to avoid TMG powder popping out of the beaker during the heat treatment. After a few minutes, no more popping was observed, and then after $10 \mathrm{~min}$ the beaker was removed from the hot plate and was placed at room temperature to cool. When we started with $100 \mathrm{mg}$ of GO, $46 \mathrm{mg}$ of TMG was usually obtained (Fig. 1). Scale-up (up to gram scale) was easily achieved with a large sized beaker. While total weight decreased after heat reduction, the volume of TMG was significantly larger than that of GO. This method requires a relatively low temperature and a short processing time (10 min of total processing time to obtain TMG materials from GO powder) and can be performed under air. The resulting TMG had been stable under air for several months when we submitted this manuscript.

Specific surface area is one of the most important characteristics for graphene-based materials. Graphene platelets with high surface area are promising candidates in ultracapacitors and in chemical/bio sensors $[1,10]$. TMG powder shows a high surface area $\left(430 \mathrm{~m}^{2} \mathrm{~g}^{-1}\right)$, as measured by BET tests. CReGO, which is produced by the reduction of an aqueous colloidal suspension of graphene oxide with hydrazine, showed a high surface area and excellent performance for ultracapacitor applications [10]. The surface area of TMG is slightly larger than that $\left(356 \mathrm{~m}^{2} \mathrm{~g}^{-1}\right)$ of $\mathrm{CReGO}$, and was measured with our BET measuring system. The morphology of TMG was examined using SEM measurements (Fig. 1). The TMG powder was not completely exfoliated as separated nano-platelets; however, it has a porous structure. This porous structure could be a reason for the high surface area of the TMG materials. 

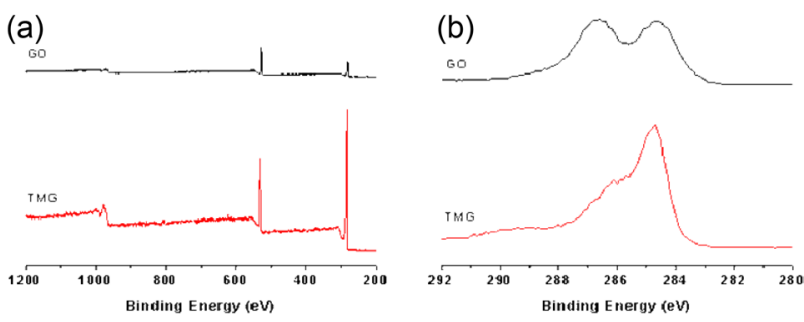

Fig. 2. XPS spectra of graphite oxide (GO) and thermally modified graphene oxide (TMG). (a) Survey scans and (b) C1s region.

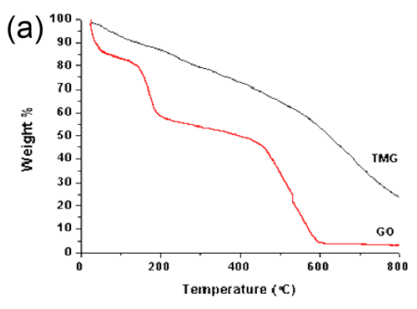

(b)

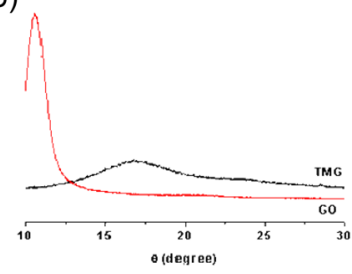

Fig. 3. (a) Thermogravimetric analysis curves and (b) X-ray diffraction patterns of graphite oxide (GO) and thermally modified graphene oxide (TMG) powders.

Successful reduction during the heat treatment of GO on the hot plate was confirmed by elemental analysis and XPS (Fig. 2). Combustion-based elemental analysis has been frequently used to determine the degree of reduction of graphite/graphene oxide. The C/O ratio ( 4.7) of TMG was significantly higher than that of GO ( 1.2), which is including the contribution of water molecules trapped in the $\mathrm{GO}$ particles $[6,8]$. The $\mathrm{C} / \mathrm{O}$ ratio means that TMG lost significant numbers of oxygen atoms. An XPS spectrum of TMG at the $\mathrm{C} 1 \mathrm{~s}$ region shows a decreased signal corresponding to the $\mathrm{C}-\mathrm{O}$ components relative to those of $\mathrm{GO}$, confirming the reduction of graphene oxide [8]. The degree of reduction of TMG materials is lower than those of CReGO and those of extremely high temperature-treated GO [6,7].

TGA measurements further support the reduction of TMG materials. A TGA graph of the GO powders shows significant weight loss $(\sim 42 \mathrm{wt} \%)$ before $200^{\circ} \mathrm{C}$, due to evaporation of water molecules inside the hydrophilic GO particles as well as to the decomposition of labile oxygen functional groups [8,11]. On the other hand, TMG powder showed a smaller weight loss $(\sim 10$ wt $\%$ ) before $200^{\circ} \mathrm{C}$. While an XRD pattern of GO showed a big peak ( 2 theta: $10.6 d$-spacing: $7.62 \AA$ ), that of TMG showed a broad peak centered at 2 theta $=16.76(d$-spacing: $5.28 \AA)$. The d-spacing value indicates interlayer distances between the graphene-based platelets. Removal of oxygen functional groups on the graphene oxide platelets and of water molecules in the interlayer galleries between platelets could decrease the d-spacing of the TMG after heat treatment $[4,8]$.

\section{Conclusions}

In conclusion, we demonstrate a facile route for the mass production of TMG materials. This method does not require high-cost or long processing time. Heat treatment of GO powder on a hot plate $\left(\sim 350^{\circ} \mathrm{C}\right)$ under air for 10 min produced TMG materials in a gram scale. TMG showed high specific surface area, as measured by BET tests, and a porous structure in SEM images. Successful reduction of TMG materials was confirmed by XPS, TGA, XRD, and elemental analysis. We think that this method could be useful to make graphene materials in large quantities for industrial applications such as energy storage materials and polymer composites.

\section{Acknowledgements}

S.P. thanks for support from Inha University.

\section{References}

[1] Zhu Y, Murali S, Cai W, Li X, Suk JW, Potts JR, Ruoff RS. Graphene and graphene oxide: synthesis, properties, and applications. Adv Mater, 22, 3906 (2010). http://dx.doi.org/10.1002/adma.201001068.

[2] Loh KP, Bao Q, Eda G, Chhowalla M. Graphene oxide as a chemically tunable platform for optical applications. Nat Chem, 2, 1015 (2010). http://dx.doi.org/10.1038/nchem.907.

[3] Park S, Ruoff RS. Chemical methods for the production of graphenes. Nat Nano, 4, 217 (2009). http://dx.doi.org/10.1038/nnano.2009.58.

[4] Park S, An J, Jung I, Piner RD, An SJ, Li X, Velamakanni A, Ruoff RS. Colloidal suspensions of highly reduced graphene oxide in a wide variety of organic solvents. Nano Lett, 9, 1593 (2009). http:// dx.doi.org/10.1021/n1803798y.

[5] Dreyer DR, Park S, Bielawski CW, Ruoff RS. The chemistry of graphene oxide. Chem Soc Rev, 39, 228 (2010). http://dx.doi. org/10.1039/B917103G.

[6] Stankovich S, Dikin DA, Piner RD, Kohlhaas KA, Kleinhammes A, Jia Y, Wu Y, Nguyen ST, Ruoff RS. Synthesis of graphenebased nanosheets via chemical reduction of exfoliated graphite oxide. Carbon, 45, 1558 (2007). http://dx.doi.org/10.1016/j.carbon.2007.02.034.

[7] RamanathanT, Abdala AA, StankovichS, Dikin DA, Herrera Alonso M, Piner RD, Adamson DH, Schniepp HC, ChenX, Ruoff RS, Nguyen ST, Aksay IA, Prud'Homme RK, Brinson LC. Functionalized graphene sheets for polymer nanocomposites. Nat Nano, 3, 327 (2008). http://dx.doi.org/10.1038/nnano.2008.96.

[8] Park S, An J, Piner RD, Jung I, Yang D, Velamakanni A, Nguyen ST, Ruoff RS. Aqueous suspension and characterization of chemically modified graphene sheets. Chem Mater, 20, 6592 (2008). http://dx.doi.org/10.1021/cm801932u.

[9] McAllister MJ, Li JL, Adamson DH, Schniepp HC, Abdala AA, Liu J, Herrera-Alonso M, Milius DL, Car R, Prud'homme RK, Aksay IA. Single sheet functionalized graphene by oxidation and thermal expansion of graphite. Chem Mater, 19, 4396 (2007). http:// dx.doi.org/10.1021/cm0630800.

[10] Stoller MD, Park S, Zhu Y, An J, Ruoff RS. Graphene-based ultracapacitors. Nano Lett, 8, 3498 (2008). http://dx.doi.org/10.1021/ n1802558y.

[11] Lerf A, Buchsteiner A, Pieper J, Schottl S, Dekany I, Szabo T, Boehm HP. Hydration behavior and dynamics of water molecules in graphite oxide. J Phys Chem Solids, 67, 1106 (2006). http:// dx.doi.org/10.1016/j.jpcs.2006.01.031. 